\title{
BOOKTRAILERS: NOVAS FORMAS DE CONSUMIR LIVROS E MICRONARRATIVAS QUE CAPTURAM O LEITOR
}

\author{
Book trailers: new ways of book consumption and \\ micronarratives to get readers
}

\section{Booktrailer: nuevas maneras de consumo de libros y micronarrativas para persuadir a los lectores}

\author{
Dora Carvalho \\ Escola Superior de Propaganda e Marketing, São Paulo, Brasil. \\ Doutoranda em Comunicação e Práticas do Consumo pelo Programa de Pós-Graduação em Comunicação e \\ Práticas de Consumo da Escola Superior de Propaganda e Marketing. Mestre em Comunicação na Contempo- \\ raneidade pela Faculdade Cásper Líbero. \\ E-mail: dora.carvalho@gmail.com
}

RESUMO Os booktrailers são hoje uma das estratégias de divulgação de lançamentos literários no mercado, a fim de atrair o leitor para as tramas apresentadas nas novas obras. A partir de conceitos como bricolagem, ready-made, gêneros discursivos da publicidade, narrativas e memória, este estudo propõe uma discussão sobre as formas utilizadas pelos publicitários para persuadir o leitor a consumir novos livros. Os autores que nos ajudam nesta análise são João Anzanello Carrascoza, José Ortega y Gasset, John Thompson, Colin Campbell, Lluís Duch, Albert Chillón y Fredric Jameson.

PALAVRAS-CHAVE Discursos Publicitários, Narrativas, Consumo, Livros, Booktrailers.

ABSTRACT Book trailers are now one of the dissemination strategies of literary releases on the market in order to attract the reader to the plots presented in new works. From concepts like bricolage, ready-made, genres of advertising, narrative and memory, this study discusses the methods used by advertisers to persuade the reader to consume new books. Authors who helped us in this analysis were John Anzanello Carrascoza, José Ortega y Gasset, John Thompson, Colin Campbell, Lluís Duch, Albert Chillon and Fredric Jameson.

KEYWORDS Advertising Speeches, Narratives, Consumption, Books, Book Trailers.

RESUMEN Los booktrailers son ahora una de las estrategias de difundir las nuevas obras literarias en el mercado editorial y de atraer a los lectores. A partir de conceptos como bricolaje, readymade, géneros de la publicidad, la narrativa y la memoria, el estudio propone una discusión sobre las formas utilizadas por los anunciantes para persuadir a los lectores a consumir nuevos libros. Los autores que nos ayudan en el análisis son John Anzanello Carrascoza, Ortega y Gasset, John Thompson, Colin Campbell, Lluís Duch, Albert Chillon y Fredric Jamesons.

PALABRAS CLAVE Discursos Publicitarios, Narrativas, Consumo, Libros, Booktrailers. 


\section{INTRODUÇÃO}

Cada vez mais, a velocidade de produção e lançamento de livros na atualidade faz a publicidade utilizar novas estratégias e plataformas de veiculação de anúncios para atingir um número cada vez maior de leitores. Atualmente, com os nichos específicos de mercado, a internet tem sido uma significativa plataforma de divulgação de novos títulos, porém apresenta uma gama de desafios que fazem os criadores das peças publicitárias usarem diversos tipos de discurso para atingir o público desejado.

O mercado literário brasileiro ao longo da última década teve um crescimento bastante expressivo. Em 2003, foram lançados 35.590 títulos; em 2013, esse montante subiu para 62.235. Os números mais atuais, conforme a pesquisa "Produção e vendas do setor editorial brasileiro", da Fundação Instituto de Pesquisas Econômicas da Universidade de São Paulo (Fipe/USP), sob encomenda da Câmara Brasileira do Livro (CBL) e do Sindicato Nacional dos Editores de Livros (Snel), indicam que as editoras brasileiras venderam, em 2013, 279,66 milhões de exemplares - um crescimento de 4,13\% em relação a 2012 (268,56 milhões).

É um setor de produção que já atingiu a casa dos 5,3 bilhões de reais em faturamento e disputa palmo a palmo um mercado consumidor em constante expansão, sendo que o crescimento dos ganhos totais desse segmento de 2012 para 2013 foi da ordem de 7,52\%, se consideradas as vendas de livros didáticos para o governo brasileiro. As livrarias físicas e virtuais detêm $61,4 \%$ das vendas do segmento, ou seja, é no ponto de venda, seja ele virtual ou convencional, que os títulos disputam a atenção dos potenciais leitores.

É nesse contexto de produção que se inserem as estratégias publicitárias do mercado livreiro, que vem trabalhando para atender a segmentos da população com diversas características e especificidades, aumentando o desafio de atrair leitores, cada vez mais especializados e exigentes. Como nos lembra Everardo Rocha, na obra Magia e capitalismo, a publicidade "antropomorfiza" os objetos - no nosso caso, o livro - e os levam a um universo simbólico. "A trajetória do produto começa na 'compreensão' do modo de sua produção e se completa na 'sensibilização' do seu modo de consumo” (1990, p. 67).

Rocha lembra que há um fluxo constante de serviços, produtos e bens a que somos submetidos e que fundamentalmente são categorizados para nós pela publicidade, que tem uma função nominadora e se utiliza da bricolagem em seu processo de criação. Ela nos dá um roteiro de sentidos, empresta conteúdo aos gêneros de produtos, fazendo deles marcas específicas dotadas de nome, lugar e significado. Atua como um operador totêmico: da mesma maneira que os homens se diferenciam entre si, a publicidade categoriza gêneros de produtos, transformandoos em marcas específicas. Além disso, articula diversos grupos sociais, criando imagens de produtos, individualizando-os e diferenciando-os. Para isso, a publicidade pode se utilizar de narrativas, fábulas e poéticas, de forma a dar novos sentidos ao consumo, sobretudo o livro, produto que ainda está em fase de maturação no mercado nacional.

A disputa acirrada pelo leitor faz as editoras brasileiras, cada vez mais, utilizarem diferentes formas de atingir potenciais compradores. As redes sociais têm sido uma maneira de fazer "ações de guerrilha" (Carrascoza, 2014, p. 255) no caminho virtual do consumidor de livros e o ajudam a divulgar lançamentos de forma espontânea. Os booktrailers utilizam o YouTube como meio de transmissão e, a partir dele, aparecem 
em diversos sites, como portais de livrarias virtuais, em conjunto com o espaço de venda dos livros, ou mesmo no site das editoras, além de serem veiculados em blogs e sites dedicados a resenhas e divulgação literária.

Dada a gama de possibilidades, a proposta deste artigo é demonstrar, por meio de booktrailers, o emaranhado de bricolagens e ready-mades (“já prontos"). Isso porque são constantemente utilizados formatos e estéticas já conhecidas do consumidor, sejam elas oriundas de outros anúncios, de imagens e símbolos clássicos do cinema ou ainda referenciais que fazem parte do repertório dos leitores-alvo dessas campanhas de lançamento. São discursos publicitários e formatos de anúncio produzidos especialmente como vídeos curtos, entre 30 segundos e pouco mais de um minuto. Seu estilo é multifacetado, e cada booktrailer assume características de acordo com a obra a ser divulgada.

É no formato de micronarrativas, com pequenos extratos do texto original, que as editoras buscam capturar a atenção dos leitores. Assim como os trailers de filmes, utilizam fragmentos das obras, montando pequenas estórias, dando pistas de personagens e oferecendo elementos de aventura, emoção, medo, desconforto e suspense. Esses booktrailers podem ter ou não texto verbal; os criadores podem utilizar imagens para ilustrar determinadas passagens das estórias, com desenhos ou pessoas e lugares que remetam ao enredo. São claros os elementos de paródia, pastiche e paráfrase, não só nos textos verbais, como também nas imagens utilizadas. Há constantemente o resgate de temas que o potencial leitor facilmente poderá identificar ou relembrar, principalmente de obras cinematográficas.

Os booktrailers seriam uma espécie de degustação rápida da obra, convidando o leitor a vivenciar a trama de forma vívida e atraente por alguns segundos, com discursos de caráter dionisíaco, já que o "apelo ao consumo não é apregoado de maneira clara e direta, muito menos imperativa, e sim apenas insinuado" (Id., 2004, p. 91).

Com o objetivo de mostrar suas diversas estratégias de persuasão, foram separados diferentes formatos de booktrailers pelas editoras atualmente. $O$ formato é relativamente novo e veio na esteira do sucesso das próprias redes sociais, sobretudo do próprio YouTube, onde são amplamente divulgados. As editoras mantêm canais próprios nessa plataforma e é nela que fazem upload (carregamento) de vídeos.

Vale destacar que, segundo uma reportagem do Exame.com (2014), o Brasil é o segundo maior mercado consumidor de vídeos do YouTube no mundo. Ao todo, 1 bilhão de usuários o acessam no mundo por mês e, a cada minuto, 100 horas de vídeos são enviadas. A rede social existe há noves anos, e 61\% de seus usuários são de fora dos Estados Unidos, país-sede da plataforma.

\section{A NECESSIDADE DA NARRATIVA}

Umberto Eco (1994) nos diz que "numa história sempre há um leitor, e esse leitor é um ingrediente fundamental não só do processo de contar uma história, como também da própria história”. Assim como o autor, Ortega y Gasset (2001) nos lembra que, para compreender algo do ser humano, seja de forma pessoal ou coletiva, é preciso contar uma história.

Pela perspectiva do indivíduo há sempre uma narrativa a ser contada, pois a vida é uma dialética entre o eu e a situação em que o sujeito se 
encontra: "eu sou eu e minhas circunstâncias", segundo o autor. A partir do próprio ponto de vista, "o homem vê a sociedade; o que crê, o que sente, o que prefere” (Ibid., p. 95).

Para Eco, o mundo ficcional tem a mesma função de um brinquedo infantil. Essa é a função consoladora da narrativa - a razão pela qual as pessoas contam histórias e têm contado histórias desde o início dos tempos (op. cit., p. 93). O mundo ficcional se apoia no mundo real. Quando se trata de ficção, o leitor usa o que se pode chamar de "preterição", ou seja, deixa de lado ou despreza alguns fatos que não têm coerência com o mundo real. Porém, o mesmo ocorre nas verdades ficcionais. O leitor acredita na realidade transmitida pela TV, por exemplo, porque em certos momentos faz o mesmo acordo de suspensão da descrença. Isso ocorre porque o leitor está diretamente ligado às condições sociais e contextos culturais aos quais está conectado e se utiliza das narrativas de vida inseridas na própria cultura para elaborar sua própria história, articulando-as com as de outros grupos sociais.

O homem sempre esteve ligado a uma "grande narrativa", ou "sistemas seculares de crenças que têm uma função mobilizadora e legitimadora”, como analisa Thompson (2007), que estão aglutinados em uma esfera do simbólico:

O que entendo com isso é que as formas simbólicas são expressões de um sujeito e para um sujeito (ou sujeitos). Isto é, as formas simbólicas são produzidas, construídas e empregadas por um sujeito que, ao produzir e empregar tais formas, estão buscando certos objetivos e propósitos e tentando expressar aquilo que ele "quer dizer" ou "tenciona" nas e pelas formas assim produzidas. (p. 183-184)

Isso significa que os sentidos que o sujeito-produtor dá a suas expressões simbólicas podem ter uma gama de ramificações, mesmo que existam regras e códigos preestabelecidos. Embora possam fazer parte, tacitamente, do cotidiano dos envolvidos, o emprego de manifestações verbais, por exemplo, ganha novos contornos, conforme o momento e a situação em que são utilizados.

Para Thompson, a contextualização das condições sociais de produção cultural é parte determinante para entender como as formas simbólicas são interpretadas e constituídas, dependendo de contextos sócio-históricos específicos. E o mais importante: "ao receber e interpretar formas simbólicas, os indivíduos estão envolvidos em um processo contínuo de constituição e reconstituição do significado, e este processo é, tipicamente, parte do que podemos chamar de reprodução simbólica dos contextos sociais” (Ibid., p. 202).

Conforme Duch e Chillón, há uma memória individual e uma coletiva embutidas nesses contextos sociais, formando a chamada memória cultural, com seus ritos, representações, símbolos, ícones, monumentos, festas tradicionais, mitos e identidades que podem ajudar ou não o sujeito a se conectar com um ou outro tipo de forma simbólica, além de fundamentar seus discursos, sendo todos os indivíduos "herdeiros de um legado social, graças ao trabalho interpretador da memória” (2012, p. 405).

Esse processo de interagir com o simbólico na forma de narrativas amplifica as formações discursivas no meio publicitário. Campbell (2001) explica que o legado da sociedade moderna para a contemporânea é a mudança na maneira com que o indivíduo lida com os próprios desejos e obtém prazer com as experiências do dia a dia. A transformação se deu na 
forma como os modos de desejar e sonhar se fundem, com um elemento de sonho entrando no próprio desejo. A atividade de consumo se dá hoje não pela seleção, compra ou uso dos produtos, mas pela idealização e projeção de um prazer imaginado anteriormente, que possa gerar identificação por parte do consumidor potencial e que possa ser associado a um sonho. Tão logo ocorra esse processo, o produto será desejado:

O consumidor moderno desejará um romance em vez de um produto habitual porque isso o habilita a acreditar que sua aquisição, e seu uso, podem proporcionar experiências que ele, até então, não encontrou na realidade. (Ibid., p. 129-131)

Vimos até aqui que o consumidor/leitor precisa de histórias e narrativas que se conectem aos contextos sociais nos quais está inserido para que possa ser motivado ao consumo. Adiante, veremos as formações discursivas da publicidade utilizadas nos booktrailers que se utilizam justamente dessa "memória pré-constituída", porque para que minhas palavras tenham sentido, é preciso que elas já façam sentido anteriormente, explica Orlandi (2013).

\section{ANÁLISES}

Faremos a análise dos discursos publicitários utilizados em quatro booktrailers a seguir, a fim de demonstrar as estratégias utilizadas pelas editoras para chamar a atenção do público para os livros. Como foi dito, são micronarrativas, extratos da história, utilizados para capturar a atenção do leitor e instigar a curiosidade para o enredo. Serão levadas em conta, por meio das frases utilizadas, em que campo discursivo eles são construídos, e delimitaremos alguns deles. O mapa semiótico geral de Andrea Semprini (1993) também ajudará a situar as peças publicitárias dos booktrailers aos campos do lúdico, utópico, prático e crítico.

O primeiro booktrailer a ser analisado é do livro Se eu ficar, de Gayle Forman (2014). Podemos perceber diversos elementos de ready-made (que se aproveitam de propostas estéticas e discursivas anteriores), porque, desde a capa do livro até a concepção do texto, obedece não apenas a obra em si, como também a produção cinematográfica que, à época do lançamento do livro, também estava prestes a estrear no Brasil, com cerca de apenas um mês de diferença entre os dois lançamentos.

Às vezes você faz escolhas na vida, e às vezes as escolhas fazem você. Essa é a beleza das coisas.
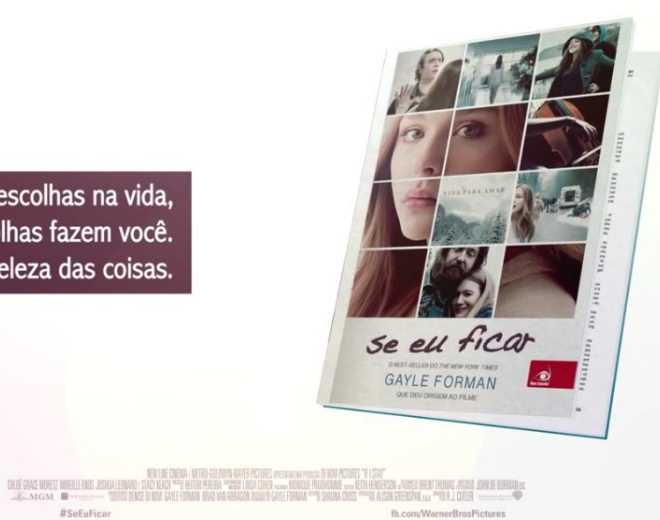

Figura 1. Booktrailer do livro Se eu ficar (Forman, 2014). 
"Às vezes, você faz escolhas na vida, e às vezes as escolhas fazem você. Essa é a beleza das coisas."

"Livro best-seller do The New York Times."

"Em apenas um dia, Mia deve tomar a maior decisão de sua vida. Uma história capaz de surpreender você.”

"Conheça a emocionante história que deu origem a um dos filmes mais aguardados de 2014."

"3 de agosto nas livrarias. 4 de setembro nos cinemas."

Esse booktrailer de 36 segundos antecede ao trailer de divulgação do próprio filme. No total, são 2'56" veiculados por meio do YouTube, porque é apresentado em conjunto com a produção cinematográfica. Há uma apropriação clara não apenas da estética do próprio filme, com fotos das cenas, como de elementos sonoros e imagens, com destaque para as fotos dos atores do longa-metragem. São dois discursos fundadores que se mesclam: livro e filme. Há aqui uma paráfrase dupla (Carrascoza, 2008), com citações tanto do campo verbal como do visual, além da ocorrência do ready-made, com o objetivo de associar um produto a outro de sucesso, no caso, o filme homônimo, dirigido por R.J. Cutler, que arrecadou US\$ 15,7 milhões na sua estreia nos Estados Unidos.

No campo textual, o booktrailer se vale de um texto de caráter dionisíaco - que costuma ser caracterizado pela emoção - e assume narrativas mais subjetivas e de forte identificação por parte do leitor. Por meio de trechos do enredo da obra, chama a atenção do consumidor/ leitor para o sucesso do livro e sua disponibilidade nas livrarias, além da estreia nos cinemas, envolvendo-o na trama da estória da escritora Gayle Forman.

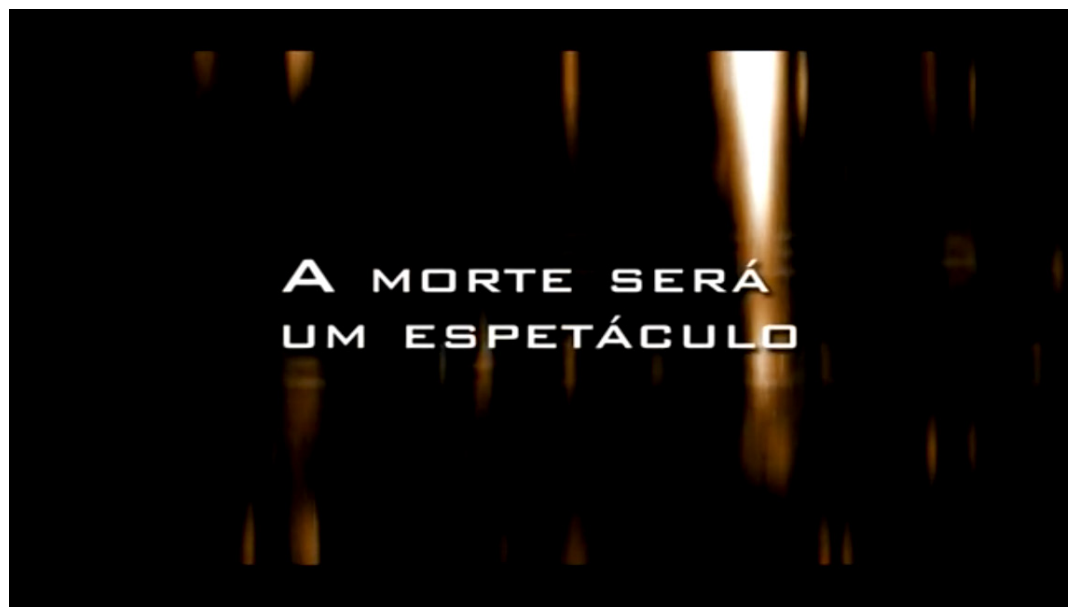

Figura 2. Trailer do filme Jogos Vorazes (2010).

"No futuro."

"A morte será um espetáculo."

"Assistido por milhões."

"Crianças serão enviadas a uma arena."

"Para lutar umas contra as outras."

"Matar ou morrer."

"Não há escolha."

"Que os jogos vorazes comecem!"

“'Jogos Vorazes é surpreendente.' Stephenie Meyer, autora da série

Crepúsculo."

"Violento, chocante... Eu não conseguia parar de ler'. Stephen King." 
“'O romance de aventura mais próximo da perfeição que eu já li’

Rick Riordan, autor da série Percy Jackson e os Olimpianos."

"Já nas livrarias."

A trilogia Jogos Vorazes é um fenômeno tanto nas livrarias como no cinema. Nas telas, a série já arrecadou US\$1,5 bilhão de dólares em bilheterias até novembro de 2014. A saga ultrapassou a marca dos 50 milhões de exemplares vendidos em todo o mundo, desde que foi lançada em 2008, pela escritora Suzanne Collins. Para o público-alvo da editora, a trama tem vários fatos facilmente reconhecidos, porque a personagem principal da trama, Katniss Everdeen, e sua intérprete nos cinemas, a atriz Jennifer Lawrence, tornaram-se símbolos fortes de sucesso entre adolescentes e fãs desse tipo de enredo.

Nesse booktrailer, de 60 segundos, privilegiou-se os elementos fortes dos três livros: a morte de crianças, que são jogadas em uma arena para uma luta desleal em uma espécie de reality show. Os testemunhais são elementos importantes aqui, pois, além de envolverem o consumidor/ leitor nos principais fatos da estória, chamam a atenção para as opiniões de autores já consagrados entre o público infantojuvenil para assegurar a qualidade de Jogos vorazes.

Embora os anúncios com testemunhais sejam normalmente de vertente apolínea - com o objetivo de ressaltar as qualidades de um produto -, ficam claras aqui as intenções dionisíacas, "pois provoca uma adesão, pela emoção, dos espíritos” (Carrascoza, 2004, p. 121). O objetivo do anúncio é deixar claro para o leitor antenado na nova safra de autores infantojuvenis que o livro de Suzanne Collins também vai agradá-lo.

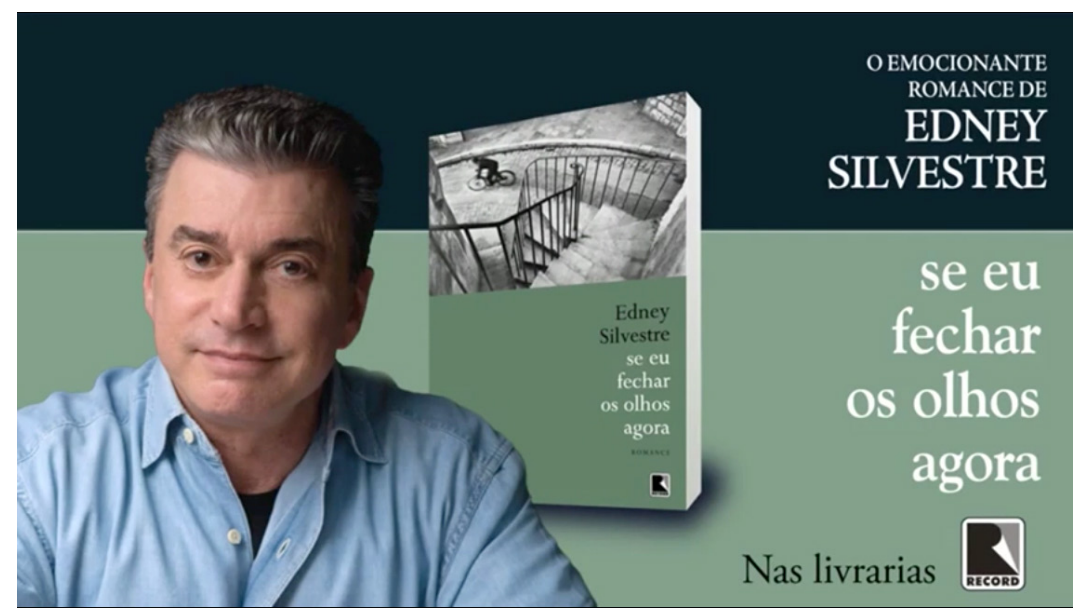

Figura 3. Booktrailer do livro Se eu fechar os olhos agora (2010).

"Num mundo em transformação."

"Em um país onde nada é o que parece."

"Dois meninos se encontram..."

"O corpo de uma mulher..."

"Brutalmente assassinada."

"Um crime que mudará para sempre suas vidas."

"O emocionante romance de Edney Silvestre, Se eu fechar os olhos agora."

"Nas livrarias."

Uma micronarrativa acontece aqui para instigar o consumidor/leitor a conhecer a saga escrita por Edney Silvestre. Mescladas com imagens 
que remetem ao mundo narrado pelo escritor, as frases aparecem nesse booktrailer de 33 segundos em um texto feito em terceira pessoa, evocando emoção, poesia e suspense. É uma narrativa dionisíaca, que tenta persuadir a partir do quadrante do lúdico, do psicológico, do surpreendente e emocionante, se levarmos em conta o seguinte mapa:

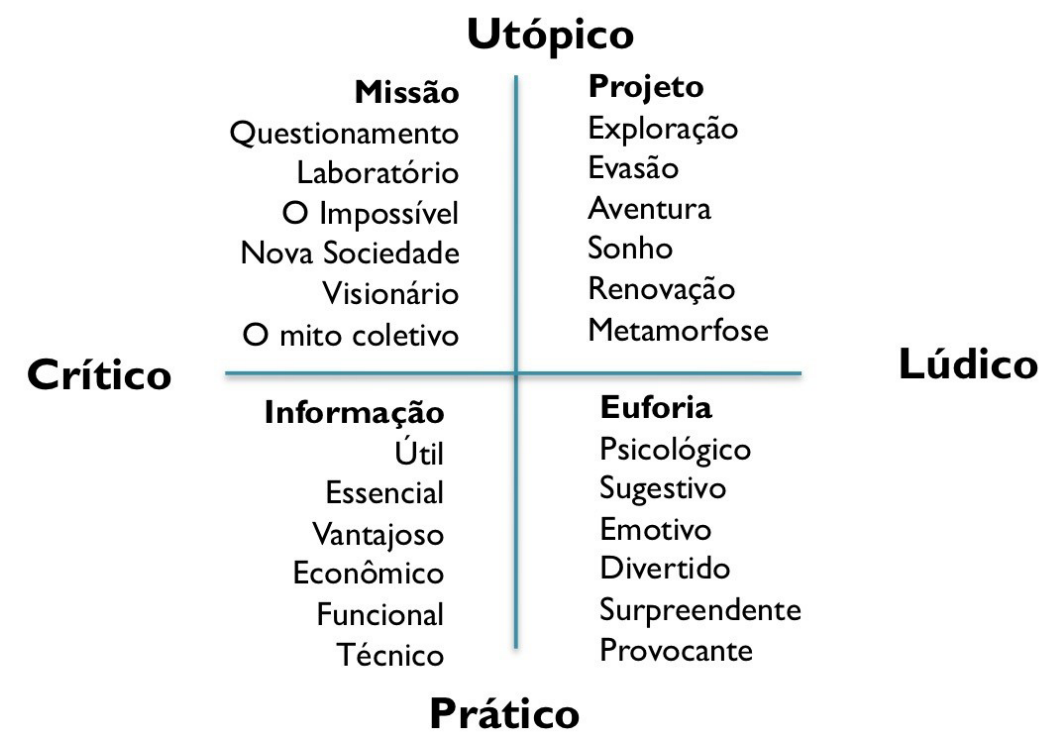

Figura 4. Mapa semiótico geral.

O mapa de Semprini (1993) nos mostra que esse booktrailer está inserido em toda a parte direita do esquema, pois sua construção está amplamente fundamentada no campo que vai do lúdico até mesmo ao utópico. O mesmo deve ocorrer com o próximo booktrailer a ser analisado.

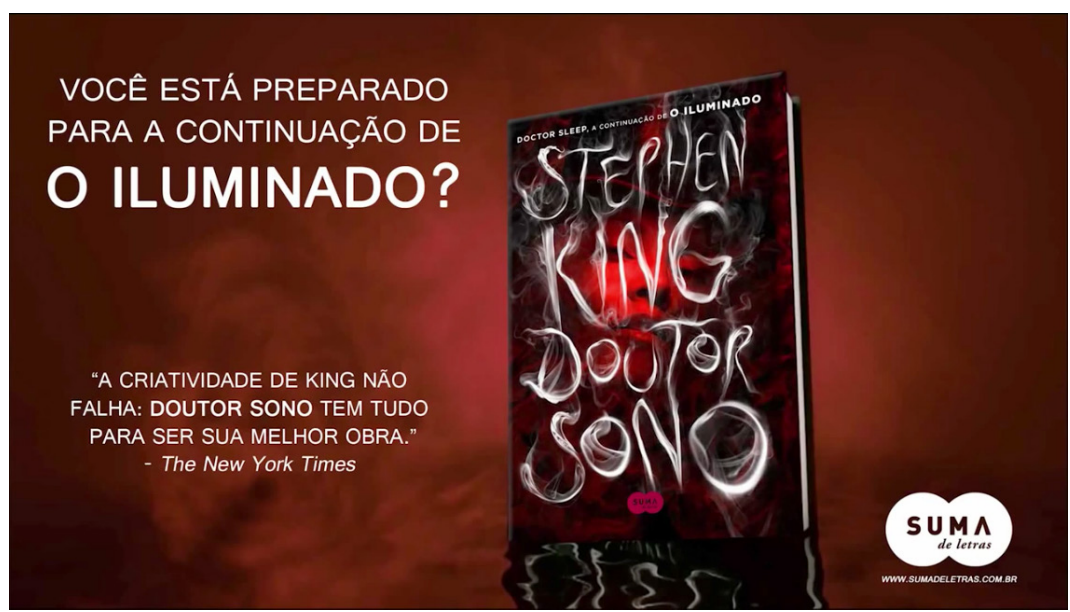

Figura 5. Booktrailer do livro Doutor Sono (2014).

"Novo livro de Stephen King."

"Viva um pesadelo..."

"A cada minuto."

"Você está preparado para a continuação de 'O iluminado'?”

"A criatividade de King não falha. Doutor Sono tem tudo para ser sua melhor obra." - The New York Times" 
O booktrailer do livro Doutor Sono é muito próximo do que estamos acostumados a ver em trailers de cinema. Intercalado por cenas com atores que transmitem a atmosfera da trama, o texto principal tem apenas três frases mescladas com imagens de terror e pesadelo, em um universo absolutamente onírico. O objetivo é causar medo e, assim sendo, vai guiando o consumidor/leitor por meio das cenas a um ápice de suspense e a um misterioso personagem, que pode ou não ser o Doutor Sono da trama. O booktrailer termina com uma questão/convite a ler a continuação de outra obra de Stephen King, O iluminado. Parte-se da ideia de que o espectador já conhece de antemão o autor e suas obras, assim como o estilo do escritor.

Há diversos elementos de "intertextualidade" (Carrascoza, 2004, p. 115) nesse booktrailer, por causa da mistura de cenas que evocam o universo de filmes, livros e séries de horror. Essa intertextualidade, que advém de referências culturais, populares ou eruditas, segundo Carrascoza, é utilizada nas criações publicitárias, deixando implícitos diálogos entre textos. O intertexto é de extrema importância no processo de persuasão, pois pode servir de chancela para validar o discurso.

Elementos dispostos de maneira a parodiar o cinema de terror, com uma miscelânea de referências, transformam o booktrailer em um pastiche. Colheres tortas que sobem ao teto de uma cozinha e depois caem, uma menina que se contorce em uma cama, objetos inanimados que voam, um texto enigmático escrito em letras de sangue em uma parede de azulejos brancos e, por fim, uma figura monstruosa de olhos vermelhos. Uma voz difusa sussurra ao fundo em inglês, demonstrando que o anúncio brasileiro é um reaproveitamento do booktrailer produzido para o mercado norte-americano - fato comum nos booktrailers nacionais. Toda estética do anúncio desse livro busca capturar o consumidor/leitor para um universo que, imagina-se de antemão, seja conhecido por quem está interessado na estória de Stephen King.

\section{CONSIDERAÇÕES FINAIS}

Jameson (2006) nos lembra que, após a Segunda Guerra Mundial, um novo tipo de sociedade começou a surgir (descrita de várias maneiras como sociedade pós-industrial, sociedade do consumo, do capitalismo multinacional etc.), apresentando novos tipos de consumo. Dela já vem uma obsolescência planejada, um ritmo ainda mais rápido de mudanças na moda e no estilo, um nível de inserção da mídia e da propaganda bastante expressivo. É aí que residem os desafios dos criadores de publicidade - no caso deste estudo, os booktrailers. A rapidez com que surgem novas sagas, modismos, adaptações cinematográficas das obras, fazendo os enredos originais ganharem novos significados e simbolismos, resulta na busca dos criativos de publicidade por uma constante adaptação dos discursos para atingir esse público, cada vez mais flutuante. Não é à toa que vimos aqui uma série de ocorrências de ready-made, paródias e pastiches nas peças analisadas.

Vimos que há a necessidade de criar narrativas que se vinculem fortemente ao universo dos potenciais leitores das obras. É preciso considerar

o que é dito em um discurso e o que é dito em outro, procurando escutar o não-dito naquilo que é dito. Isso porque só uma parte do dizível é acessível ao sujeito, pois mesmo o que ele não diz significa em suas palavras. (Orlandi, 2013, p. 34) 
Ou seja, é preciso encontrar nos discursos dos próprios leitores as referências necessárias para que essas peças ativem sua memória e suas referências culturais.

Este estudo permitiu observar ainda que novas vertentes e plataformas de veiculação de publicidade se fazem presentes, propondo novos desafios para os criadores das peças e um maior aprofundamento nas pesquisas sobre discursos publicitários da atualidade. É preciso destacar também que os discursos da publicidade funcionam como um motor de consumo, segundo Rocha (1990), envolvendo os produtos em um universo de fábulas e imagens.

\section{REFERÊNCIAS}

'JOGOS vorazes 3' perde em bilheteria para antecessores. Veja.com, São Paulo, 24 nov. 2017. Disponível em: <http://abr.ai/2okm2kj>. Acesso em: 10 abr. 2017.

BOOKTRAILER: Se eu ficar - Gayle Forman. 2'56". Grupo Editorial Novo Conceito. YouTube. 2014. Disponível em: <http://bit.ly/2nyHfZ9>. Acesso em: 10 abr. 2017.

BOOKTRAILER Doutor Sono: Stephen King. 0'32". Editora Objetiva. YouTube. 2014. Disponível em: <http://bit.ly/2nW1FGS>. Acesso em: 10 abr. 2017.

CAMPBELL, C. A ética romântica e o espirito do consumismo moderno. Rio de Janeiro: Rocco, 2001.

CARMELO, B. Bilheterias Estados Unidos: Guardiões da Galáxia volta ao topo, Se eu ficar é a melhor estreia. Disponível em: <http://bit.ly/1nzVcKY>. Acesso em: 10 abr. 2014.

CARNEIRO, R. O mundo cruel (e rentável) da distopia infantojuvenil. 2013. Disponível em: <http://abr.ai/2p08Lfd>. Acesso em: 10 abr. 2014.

CARRASCOZA, J. A. A cena do consumo no anúncio clássico e na guerrilha publicitária. In: ROCHA, R. M.; OROFINO, M. I. R. (Org.). Comunicação, consumo e ação reflexiva: caminhos para a educação no futuro. Porto Alegre: Sulina, 2014.

Do caos à criação publicitária: processo de criativo, plágio e ready-made na publicidade. São Paulo: Saraiva, 2008.

. Razão e sensibilidade no texto publicitário. São Paulo: Futura, 2004.

DUCH, L.; CHILLÓN, A. Un ser de mediaciones. Barcelona: Heder, 2012.

FORMAN, G. Se eu ficar. São Paulo: Novo Conceito, 2014.

JAMESON, F. A virada cultural. Rio de Janeiro: Civilização Brasileira, 2006.

JOGOS vorazes: booktrailer. 0'59'. Editora Rocco. YouTube. 2010. Disponível em: <http:// bit.ly/2oZTZoO>. Acesso em: 10 abr. 2017.

KING, S. Doutor Sono. São Paulo: Suma de Letras, 2014

ORLANDI, E. Análise do discurso: princípios e procedimentos. Campinas: Pontes, 2013.

ORTEGA Y GASSET, J. Historia como sistema. Madri: Biblioteca Nueva, 2001.

ROCHA, E. G. Magia e capitalismo: um estudo antropológico da publicidade. São Paulo: Brasiliense, 1990.

SEMPRINI, A. Marche e mondi possibili: un approccio semiotico al marketing della marca. Milão: Franco Angeli, 1993.

SILVESTRE, E. Se eu fechar os olhos agora. São Paulo: Record, 2014.

THOMPSON, J. B. Ideologia e cultura moderna. Rio de Janeiro: Vozes, 2007.

YOUTUBE afirma que Brasil é o segundo país em consumo de vídeos do portal. Exame.com, São Paulo, 28 jul. 2014. Disponível em: <goo.gl/vlfM50>. Acesso em: 10 abr. 2017.ljogos 